\title{
Life-history genomic regions explain differences in Atlantic salmon marine diet specialization
}

\section{Aykanat, Tutku}

2020-11

Aykanat , T , Rasmussen , M , Ozerov , M , Niemelä , E , Paulin , L , Vähä , J-P , Hindar , K, Wennevik, V , Pedersen , T , Svenning , M-A \& Primmer , C R 2020 , ' Life-history genomic regions explain differences in Atlantic salmon marine diet specialization ' , Journal of Animal Ecology , vol. 89 , no. 11 , pp. 2677-2691 . https://doi.org/10.1111/1365-2656.13324

http://hdl.handle.net/10138/335863

https://doi.org/10.1111/1365-2656.13324

Downloaded from Helda, University of Helsinki institutional repository.

This is an electronic reprint of the original article.

This reprint may differ from the original in pagination and typographic detail.

Please cite the original version. 


\title{
Life-history genomic regions explain differences in Atlantic salmon marine diet specialization
}

\author{
Tutku Aykanat $^{1}$ (D) | Martin Rasmussen ${ }^{2}$ | Mikhail Ozerov ${ }^{3,4}$ (i) | Eero Niemelä ${ }^{3,5}$ | \\ Lars Paulin $^{6}$ | Juha-Pekka Vähä ${ }^{7}$ | Kjetil Hindar ${ }^{8}$ | Vidar Wennevik ${ }^{9}$ | \\ Torstein Pedersen $^{2}$ | Martin-A. Svenning ${ }^{10}$ | Craig R. Primmer ${ }^{1,6}$ (D)
}

${ }^{1}$ Organismal and Evolutionary Biology Research Programme, Faculty of Biological and Environmental Sciences, University of Helsinki, Helsinki, Finland; ${ }^{2}$ Department of Arctic and Marine Biology, UiT The Arctic University of Norway, Tromsø, Norway; ${ }^{3}$ Department of Biology, University of Turku, Turku, Finland; ${ }^{4}$ Kevo Subarctic Research Institute, University of Turku, Turku, Finland; ${ }^{5}$ Natural Resources Institute Finland (Luke), Oulu, Finland; ${ }^{6}$ Institute of Biotechnology, University of Helsinki, Helsinki, Finland; ${ }^{7}$ Association for Water and Environment of Western Uusimaa, Lohja, Finland; ${ }^{8}$ Norwegian Institute for Nature Research (NINA), Trondheim,

Norway; ${ }^{9}$ Institute of Marine Research (IMR), Bergen, Norway and ${ }^{10}$ Arctic Ecology Department, Norwegian Institute for Nature Research (NINA), Troms $\varnothing$, Norway

Correspondence

Tutku Aykanat

Email: tutku.aykanat@helsinki.fi

\section{Funding information}

Acedemy of Finland, Grant/Award Number: 314254, 314255, 318939 and 325964; Atlantic salmon in the Barents Region, Grant/Award Number: KO197; Research Council of Norway, Grant/Award Number: 244086 and 280308

Handling Editor: Chris Harrod

\section{Abstract}

1. Animals employ various foraging strategies along their ontogeny to acquire energy, and with varying degree of efficiencies, to support growth, maturation and subsequent reproduction events. Individuals that can efficiently acquire energy early are more likely to mature at an earlier age, as a result of faster energy gain which can fuel maturation and reproduction.

2. We aimed to test the hypothesis that heritable resource acquisition variation that covaries with efficiency along the ontogeny would influence maturation timing of individuals.

3. To test this hypothesis, we utilized Atlantic salmon as a model which exhibits a simple, hence trackable, genetic control of maturation age. We then monitored the variation in diet acquisition (quantified as stomach fullness and composition) of individuals with different ages, and linked it with genomic regions (haploblocks) that were previously identified to be associated with age-at-maturity.

4. Consistent with the hypothesis, we demonstrated that one of the life-history genomic regions tested (six6) was indeed associated with age-dependent differences in stomach fullness. Prey composition was marginally linked to six6, and suggestively (but non-significantly) to vgll3 genomic regions. We further showed Atlantic salmon switched to the so-called 'feast and famine' strategy along the ontogeny, where older age groups exhibited heavier stomach content, but that came at the expense of running on empty more often.

5. These results suggest genetic variation underlying resource utilization may explain the genetic basis of age structure in Atlantic salmon. Given that ontogenetic diet has a genetic component and the strong spatial diversity associated with these genomic regions, we predict populations with diverse maturation age will have diverse evolutionary responses to future changes in marine food web structures. 


\section{KEYWORDS}

Atlantic salmon, diet specialization, life-history evolution, ontogenetic diet shift, ontogenetic foraging variation

\section{1 | INTRODUCTION}

Diet acquisition is a strong evolutionary force that can shape population demography and abundance, and is an integral determinant of ecosystem functions (Bolnick \& Araujo, 2011; Engen \& Stenseth, 1989; Svanback \& Persson, 2004). Individuals exhibit differences in prey preference and prey acquisition efficiency, which, if heritable, may be a target of selection and ultimately promote ecological specialization (Devictor et al., 2010; Fox \& Morrow, 1981; Smith \& Skulason, 1996). Large-scale disturbances in community structure, for example, as a result of climate change (Sydeman, Poloczanska, Reed, \& Thompson, 2015) alter food web structures and the composition of available resources (Bentley, Serpetti, \& Heymans, 2017; Daufresne, Lengfellner, \& Sommer, 2009; Pershing et al., 2015), forcing species to rapidly adapt to new diet landscapes. Therefore, understanding the underlying mechanisms shaping food acquisition strategies is fundamental to evolutionary biology and vital for predicting species survival in a changing world.

If heritable, inter-individual variation in resource acquisition strategies may have complex evolutionary consequences mediated by trade-offs between energy gain and survival across density- and frequency-dependent fitness landscapes (Mousseau, Sinervo, \& Endler, 2000; Reznick, 2016; Reznick \& Ghalambor, 2001; Sexton, Montiel, Shay, Stephens, \& Slatyer, 2017). For example, increased boldness to improve resource acquisition success may come at the expense of higher predation risk, the fitness costs of which may be linked to predator densities (Bolnick et al., 2011; Carter, Goldizen, \& Tromp, 2010; Gotthard, 2000). Likewise, the composition and abundance of available resources may alter the demographic structure of a population (e.g. Enberg et al., 2012; Heino \& Kaitala, 1999). Fast growth at an early age, for example, as a result of abundant food sources during the initial stages of life, may result in early maturation and hence a younger age at reproduction. In contrast, resource limitation due to high population densities results in increased allocation to somatic growth to improve size-dependent intraspecific competition (e.g. Reznick \& Endler, 1982).

Ontogenetic diet shifts in organisms may be viewed as a special type of resource acquisition strategy in which diet variation is expressed as a function of age. Ontogenetic diet shift is a significant source of variation in species' diet breadth, especially among size- and age-structured organisms, such as fishes. In general, relatively large and/or old individuals shift towards feeding at higher trophic levels and/or on larger prey items to maintain a positive energy balance (Jensen, Kiljunen, \& Amundsen, 2012; Mittelbach \& Persson, 1998; Werner \& Gilliam, 1984). Under changing food web dynamics, diet specialization among different age groups may substantially influence the demographic structure and life-history diversity (Sanchez-Hernandez, Nunn, Adams, \& Amundsen, 2019). For example, changes in resource composition that favour younger age groups would improve growth and subsequently increase the rate of maturation and the probability of survival at early ages. Ontogenetic diet shift is associated with a suite of changes in an individual's morphology, physiology and behaviour to maximize the efficiency of particular resources at a given ontogenic stage, perhaps at the expense of reduced efficiency at other stages (Claessen \& Dieckmann, 2002).

If ontogenetic diet variation has a genetic basis, then some individuals in a population may be selected for high prey acquisition efficiency early in their life history (via physiological or morphological trade-offs towards efficient exploitation at earlier stages), even if this may come at a cost of compromised energy acquisition at later stages in life (Claessen \& Dieckmann, 2002). We predict that such genetically driven trade-offs in resource acquisition efficiency between early and late stages mediate the age structure (i.e. maturation timing) and abundance within and among populations and maintain genetic variation in resource acquisition strategies, but such examples in the wild are rare.

Atlantic salmon Salmo salar is a fish species recognized as a diet generalist and an opportunistic feeder with extensive ontogenetic and stage- and space-structured individual variation in diet breadth (Erkinaro, Dempson, Julkunen, \& Niemelä, 1997; Haugland, Holst, Holm, \& Hansen, 2006; Hvidsten et al., 2009; Jacobsen \& Hansen, 2001; MacKenzie et al., 2012; Rikardsen \& Dempson, 2010). At sea, where most growth occurs, salmon increasingly feed on prey at higher trophic levels as they grow and age (Jacobsen \& Hansen, 2001; Rikardsen \& Dempson, 2010). The time salmon spend at sea prior to maturation (sea age at maturity) also varies greatly within and among populations (Friedland \& Haas, 1996). Although the functional and physiological basis underlying age at maturity is not entirely known, it is considered to be a threshold trait, whereby higher lipid deposition is associated with early maturation (Friedland \& Haas, 1996; Jonsson \& Jonsson, 2011; Jonsson, Jonsson, \& Hansen, 1997; Taranger et al., 2010; Thorpe, Mangel, Metcalfe, \& Huntingford, 1998). Therefore, variation in resource acquisition may be a strong determinant of the life-history variation in salmon and a trait via which natural selection can act and result in adaptive genetic changes in populations.

In Atlantic salmon, two genomic regions on chromosomes 9 and 25 have been identified to have a disproportionate influence on life-history strategy and population differentiation within and among populations (Aykanat et al., 2019; Ayllon et al., 2015; Barson et al., 2015; Czorlich, Aykanat, Erkinaro, Orell, \& Primmer, 2018; Pritchard et al., 2018). The so-called vgll3 and six6 genomic regions are named after the most prominent genes in their respective 
haploblocks on chromosomes 25 and 9 respectively. The vgll3 genomic region on chromosome 25 has been shown to be associated with age at maturity (intially by GWAS, see: Ayllon et al., 2015; Barson et al., 2015), iteroparity (Aykanat et al., 2019) and precocious male maturation in Atlantic salmon (Debes et al., 2019; Lepais, Manicki, Glise, Buoro, \& Bardonnet, 2017). This genomic region also exhibits strong spatial divergence (Barson et al., 2015; Pritchard et al., 2018), and it has recently been shown to have been affected by natural selection over the last 36 years (equivalent to 4-6 salmon generations) in parallel to the changing age structure in a large salmon population (Czorlich et al., 2018). The six6 region on chromosome 9 is associated with sea age at maturity at the population level as a result of the strong correlation between the average allele frequency and average maturation age of populations (Barson et al., 2015). This region also exhibits the strongest signal of differentiation among European populations (Barson et al., 2015) and Tana/Teno River populations (Pritchard et al., 2018) and is hence distinguished as a critical genomic region for local adaptation. Genes found in these haploblocks appear to have a role in adipose or energy metabolism regulation in other organisms. The vgll3 gene is an adipocyte inhibitor, the expression of which is correlated with body weight and gonadal adipose content in mice (Halperin, Pan, Lusis, \& Tontonoz, 2013). Recently, a strong selective sweep near the vgll3 gene was postulated to be due to energy metabolism effects in humans in Mongolia (Nakayama, Ohashi, Watanabe, Munkhtulga, \& Iwamoto, 2017). In turn, genes in the six6 genomic region are involved in cell growth, cell differentiation, apoptosis in human cell lines (PPM1A, Lin et al., 2006), and myogenesis and skeletal muscle cell proliferation in zebrafish (six $1 b$, Bessarab, Chong, \& Korzh, 2004; O'Brien, Hernandez-Lagunas, Artinger, \& Ford, 2014; Ridgeway \& Skerjanc, 2001) and act as an evolutionarily conserved regulator of eye development and the pituitary-hypothalamic axis (six6, Gallardo et al., 1999; Serikaku \& Otousa, 1994; Toy, Yang, Leppert, \& Sundin, 1998). Collectively, this suggests that the vgll3 and six6 haploblocks might have broad-scale roles in reproductive and life-history strategies in Atlantic salmon. However, how polymorphism in these regions may be translated to functional differences expressed in the wild is unclear.

Here our objective was to test whether age-dependent differences in food acquisition efficiency are associated with the vgll3 and six6 genomic regions and discuss their role in explaining the genetic variation in age structure. We achieved this goal by assessing stomach content data from adult Atlantic salmon sampled along the coast during spawning migration and genotyping the same individuals for the vgll3 and six6 genomic regions using a targeted sequencing approach. Using a modelling framework that accounted for potentially confounding environmental and phenotypic variables, we tested whether variation in diet and resource acquisition strategies had a genetic component explained by the age at maturity-linked genomic regions. Elucidating the genetic interplay between age at maturity and diet breadth is crucial to better understand the dynamics and evolution of ecological specialization and to better predict future demographic changes in Atlantic salmon populations under climate change.

\section{2 | MATERIALS AND METHODS}

\section{1 | Sample collection}

As part of a larger effort within the project 'Sea salmon fishery, resource and potential (KolaRCTIC)', Atlantic salmon S. salar, on their return migration to spawning grounds, were sampled and stomachs were collected between mid-May and late July in 2008 by local sea fishers with bend nets or bag nets along the Finnmark coast, northern Norway (Svenning et al., 2019, Figure 1). Sampled fish were measured (fork length, $\mathrm{cm}$ ) and weighed ( $\mathrm{g}$ ); their sex and maturity were identified and stomachs were frozen for later diet analysis. In addition, scales were sampled from all fish for sea age determination, categorization as wild or farmed fish according to ICES guidelines (ICES, 2011; Svenning et al., 2019) and genetic analysis. The species composition of the diet was then identified to species by visual inspection of the morphology of prey remains and otoliths which were compared to a reference collection with known species identity, with uncertain cases further inspected using keys (Härkönen, 1986; Pethon \& Nyström, 2005). All prey items, including unidentified digested remains were weighed (wet mass at a precision of $0.1 \mathrm{~g}$ ). The identifiable portion of the diet in the dataset was overwhelmingly comprised of four fish species: sand eel Ammodytes spp., capelin Mallotus villosus, herring Clupea harengus and haddock Melanogrammus aeglefinus, (see Section 3 for details). In the interest of analytical brevity, a few rare prey species were handled as follows: one gadoid fish was grouped with haddocks, both of which belong to the Gadiformes order, and negligible amounts of krill, other crustaceans and Liparidae ( $0.2 \%$ of the total stomach weight) were categorized together with the unidentified material.

\section{2 | DNA extraction, microsatellite genotyping and SNP genotyping by targeted sequencing}

DNA was extracted from scales either using a QIAamp 96 DNA QIAcube HT Kit (Qiagen) following the manufacturer's protocol or according to Elphinstone, Hinten, Anderson, and Nock (2003). Microsatellite genotyping of 31 markers was performed as outlined in Ozerov et al. (2017). Samples were further genotyped by targeted sequencing at 173 SNP markers and the sex determination locus (sdy) using a GTSeq approach (Campbell, Harmon, \& Narum, 2015) as outlined in Aykanat, Lindqvist, Pritchard, and Primmer (2016), with some modifications, so the genotyping panel was compatible with the Illumina platform. More specifically, 174 genomic regions were first amplified in one multiplex PCR using locus-specific primers with truncated Illumina adapter sequences and using primer concentrations re-optimized for the Illumina platform (Table S1). The PCR products were then treated with Exonuclease I and FastAP Thermosensitive Alkaline Phosphatase (Thermo Fisher) to remove unused primers and nucleotides. After the treatment, the products were re-amplified with adapter-specific primers containing Illumina and sample-specific dual-indexes. The index set was 


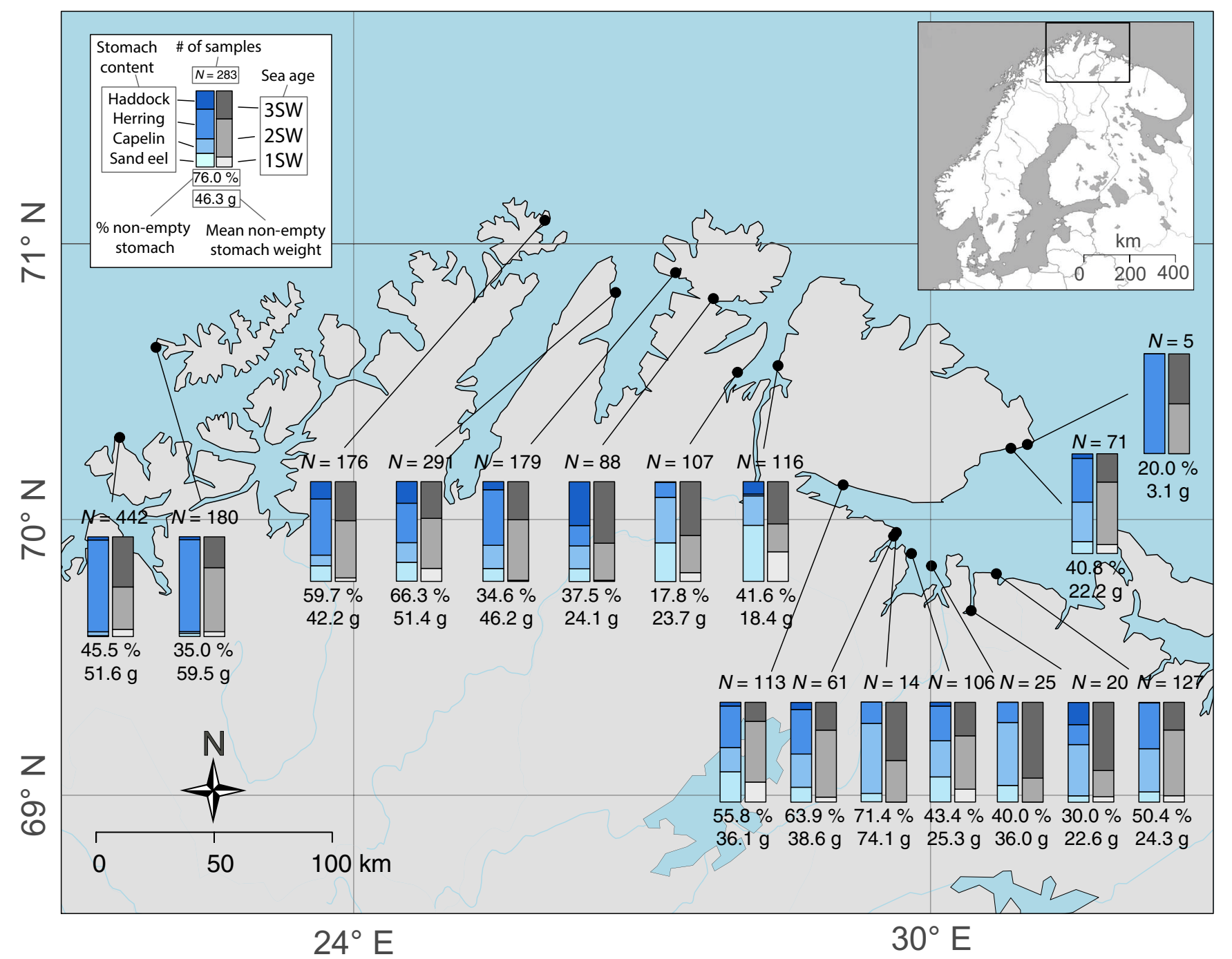

FIGURE 1 Map of the study region including sampling locations and a description of age and stomach content distributions and, sample sizes in each sampling location. See the inset key for a description of the parameters of the spatial distributions given on the map

optimized using the BARCOSEL software (Somervuo et al., 2018). The PCR products were then pooled, purified and quantified with a Qubit 2.0 fluorimeter (Thermo Fisher) and analysed on a fragment analyser (Agilent Technologies). The pooled library was then size selected using BluePippin (Sage Sciences) to remove short unspecific products and checked on a fragment analyser. Finally, samples were single-end sequenced using a 150-cycle high-output sequencing kit on a NextSeq 500 Illumina Sequencer following the manufacturer's guidelines. Loci with coverage over 12x were scored as in Aykanat et al. (2016). To calculate coverage for each SNP, raw genotype files (fastq) were scanned for every SNP, and the coverage was determined by counting sequences that matched SNP's forward and reverse primer sequences, and the $9 \mathrm{bp}$ region around the SNP site. Finally, genotypes were scored based on coverage ratios between alleles: Ratio ${ }_{\text {Cov(allele1/allele2) }}>10$ was assigned as homozygous for allele 1 , Ratio ${ }_{\text {Cov(allele1/allele2) }}<0.1$ was assigned as homozygous for

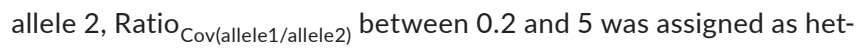
erozygous and any proportion in between was discarded (see also, Campbell et al., 2015).
Two focal SNPs used in the analyses were vgll $3_{\text {TOP }}$, which exhibits the strongest signal of association with age at maturity in the vgll3 genomic region, and six $6_{\text {TOP.LD }}$ in the six 6 haploblock on chromosome 9 , the region that exhibited the second strongest association with sea age at maturity prior to population structure correction and is $34.5 \mathrm{~kb}$ away from and in complete linkage disequilibrium with the six6 ${ }_{\text {TOP }}$ SNP reported in Barson et al. (2015).

\subsection{Genetic stock identification (GSI)}

In total, 2023 samples that had greater than $80 \%$ success in regard to microsatellite genotyping were assigned to their population of origin with 31 microsatellite markers as described in Svenning et al. (2019) using the Bayesian GSI methodology described in Pella and Masuda (2001) and implemented in cBayes 5.0.1 (Neaves, Wallace, Candy, \& Beacham, 2005). In brief, the samples were allocated into 18 analysis groups, that is, the combination of two time periods (May-June and July) and 10 fisheries regions, with each 
group consisting of 30-288 samples for analysis. The GSI analyses were performed using five independent Monte Carlo Markov chains of $100 \mathrm{~K}$ iterations starting from three random stocks (StartStock parameter), and the last $10 \mathrm{~K}$ iterations of each chain were combined and used to assign individuals to their population of origin to remove the influence of initial starting values. The baseline population data for the GSI analysis included genetic information on 185 Atlantic salmon populations spanning from the Pechora River (Russia) in the east to the Beiarelva River (Norway) in the west (see details in Ozerov et al., 2017).

The probability $(p)$ threshold for assignment of an individual to a population was set at $\geq 0.7$ following Vähä et al. $(2011,2014)$ and Bradbury et al. (2015). The $30 \%$ of individuals assigned to a population with lower confidence were kept in the dataset with the highest ranked population assigned as the population of origin. Samples with no assignment due to low genotyping success with microsatellites (4\%) were assigned a population of origin using genotype information from the SNP panel. In such cases, individuals were assigned to the population in which they exhibited the highest genetic similarity. This was measured according to the average genetic similarity of focal individuals to the individuals in each population (as inferred with the GSI analysis in the previous step) using the A.mat function in the RRBLUP package (Endelman, 2011) A small subset of individuals ( $N=16,<1 \%$ ) with poor genotyping success with SNPs ( $<50$ SNPs with high quality genotypes) was randomly assigned to a population, in which population assignment probability is weighted over the total number of individuals that were assigned by GSI. The effect of including incomplete population assignment was assessed for the main analysis by repeating the analysis but only including confidently assigned individuals.

Missing data points for some variables were inferred from highly correlated variables. In that regard, missing sea age information (i.e. due to unclear formation of sea annulus for detecting the correct sea age for some first time spawners) was inferred from length data for $15(0.7 \%)$ individuals, where the likelihood of age, given the length, was substantially higher (>20 times) for the inferred age group than for other age groups. Additionally, for 21 (1.0\%) individuals with missing length data, fit using coefficients of log(weight) to $\log$ (length) regression (adjusted $R^{2}=0.94$ ) was used to estimate the length information from the weight data. Finally, data for $33(1.6 \%)$ individuals with missing vgll $3_{\text {TOP }}$ genotype scores were inferred from the genotype score of an adjacent SNP marker in the genotyping panel, vgll3 $3_{\text {Met54Thr }}$ which is in close physical proximity to vgll3 $3_{\text {TOP }}$ with high linkage disequilibrium $\left(r^{2}=0.79\right)$.

\subsection{Genetic and ecological basis of the diet scope}

Unless otherwise noted, all statistical analyses were performed in R software v.3.2.5 (R Core Team, 2018). Either a two-component hurdle model (with binomial and the conditional negative binomial components) using the GLMMTMB package (Brooks et al., 2017) or a binomial model (with a log link function) using the gamm function in the MGCV package (Wood, 2011) was employed as the statistical model. In all models, population of origin was included as a random term to account for background population effects. To control for spatio-temporal variation, sampling location (longitude) and the day of sampling (Julian day, zero centred and scaled to one standard deviation) were included as smoother terms. Longitude, explained $90.7 \%$ of the spatial variation (i.e. sampling locations mostly occurred along a longitudinal axis, see Figure 1 and were included in the models as a surrogate for the two-dimensional spatial distribution to decrease the parametrization of the model). In addition to including the genetic variation in the six 6 and vgll3 genomic regions additively in the model (i.e. genotypes coded as a continuous factor with heterozygotes coded as the average of two homozygotes), age at maturity (e.g. Fleming, 1996) and residual length (log transformed total length after controlling for age at maturity) were also included in the model as categorical and continuous variables respectively. All numeric variables were centred and scaled. For both genomic regions (six6 and vgll3), alleles associated with late and early age at maturity were labelled as $L$ and $E$ respectively.

The general model structure was as follows:

$$
Z=S A+\operatorname{res}_{S A}+V_{S A}+S_{S A}+s(D)+s(L)+p+e,
$$

where $Z$ is the vector of response variables given as a function of sea age (SA), scaled residual length and vgll3 and six6 genotypes nested within sea age (res $L_{S A}, V_{S A}$ and $S_{S A}$, respectively), the smoother functions of sampling day $(D)$ and location $(L)$ and normally distributed random variance due to the population ( $p$ ) and individual (residual) effects. The genotypes were coded additively as 1, 2 and 3 (for EE, EL and LL respectively). In the model, the scaled genotypes and residual length were analysed independently within sea age group (i.e. nested model), which provided a statistical framework suitable for testing hypotheses related to ontogenetic diet structure. In this model, a small number of $4 \mathrm{SW}$ individuals $(N=15,0.7 \%$, SW denotes number of winters salmon spent at sea prior to sampling) was grouped and analysed within the 3SW for statistical coherence of the nested model. Models also accounted for spatio-temporal variation in the diet with smoothing spline functions. When using the GAMM package, which provides a platform for generalized additive models, days and location were modelled with a smooth function $(s())$. When using GLMMTMB package, which provides a platform for hurdle models but cannot directly model the smoother functions, an orthogonal spline design matrix with a low-rank thinplate function was generated using the spl function in the MCMCGLMM package (Hadfield, 2010) in R and included in the model as fixed terms as a surrogate for the spatio-temporal spline functions. The number of knot points ( $k$, which defines the curvature of the spline function) was set to five for both variables, but the results were robust to an increase in the $k$ value, which did not qualitatively change the results (data not shown).

A number of variables pertaining to the diet content data were used as response variables in this study. Conceptually, these variables are linked to different aspects of diet acquisition mechanisms of this species (e.g. Arrington, Winemiller, Loftus, \& Akin, 2002) and 
may indicate different functional aspects associated with performance and life-history variation among individuals.

1. The presence and amount of total diet content in the stomach: We used a two-component hurdle model to simultaneously account for stomach content quantity and empty stomach probability. By this, we tested for the prevalence of the 'feast and famine' diet acquisition strategy in Atlantic salmon as a function of ontogeny and genotype, whereby large piscivorous fish species are predicted to experience prolonged periods with empty stomachs in the interest of acquiring a high quantity of food (Armstrong \& Schindler, 2011; Arrington et al., 2002). Both components in the hurdle model included the same set of covariates (as described above). A logistic model with a log link was used to model the probability of the presence of a prey item, whereas a zero truncated negative binomial model with a log link was utilized as the conditional component. In this analysis, the total stomach weight, which had excess zero elements and a right-tailed continuous distribution (ranging from 0.5 to $393.3 \mathrm{~g}$ ), was transformed to a discrete distribution by arbitrarily binning the total weight in $10 \mathrm{~g}$ increments, with zero stomach content set as the first bin at a value of zero (Figure S1). This transformation provided a distribution that can be modelled with the hurdle framework in the GLMMTMB package (Brooks et al., 2017). Finally, we also repeated the analysis by only including confidently assigned individuals in order to assess the robustness of model to incomplete population assignment.

2. Total number and average weight of prey items in the stomach: An increase in the total prey weight in the stomach can be explained either by an increase in prey number or an increase in the average prey weight. Therefore, we next investigated the contribution of these two components in terms of explaining the model using the same statistical framework as above. Similar to the total prey weight, the average prey item weight (ranging between 0.2 and $300.2 \mathrm{~g}$ ) was also transformed to discrete units by arbitrarily binning the data at $5 \mathrm{~g}$ intervals, with zero stomach content set as the first bin (Figure S1).

3. Relative prey composition: Finally, to test whether sea age, size at age or genotype is associated with specific prey species, we modelled the prey composition, measured as the proportion of a specific prey species contributing to the stomach content weight. The proportion of each of the four prey species in the total prey weight was modelled as a response variable using binomial regression in the MGCV package (Wood, 2011).

Extensively digested, unidentified content in the stomach $(4.5 \%$ of the total stomach weight) was not treated as diet material in order to accurately reflect the recent feeding activity (e.g. Jacobsen \& Hansen, 2001). For all models, the effect size and confidence intervals were calculated with 10,000 parametric permutations of the model coefficients. To account for potential spurious inflation associated with genotype, that is, due to cryptic family structure, the analytical pathway was repeated using 168 independent and putatively neutral markers that are present in the SNP panel, and focal SNPs were ranked across the background genetic effect (by comparing the genetic model and the null model at each SNP marker). Throughout the MS, for values $<0.1$ and $>0.001$, we reported exact $p$-values and provided $95 \%$ confidence intervals with the estimates. Understanding the genetic association between diet and life-history variation in the wild is poorly unexplored. Due to this, coupled with the noisy nature of diet studies, we highlight alpha value $=0.1$ as a non-significant but suggestive cut-off value to facilitate future research directions and encourage replication.

\section{3 | RESULTS}

The final dataset contained 2,121 individuals after excluding previously spawned and escaped farmed salmon. In the final dataset, 93.3\% of the samples had visibly detectable developing gonads, confirming concordance between sea age and sea age at maturity. A total of $1,372(64.7 \%)$ individuals were confidently assigned to a population of origin ( $p>0.7)$, and $(N=651)$ Individuals assigned to a population with lower confidence $(p<0.7,30.7 \%)$. A further 82 individuals (3.9\%) with low genotyping success with microsatellites were assigned a population of origin using SNP data and 16 individuals $(<1 \%)$ lacking reliable genotypes with either set of genetic markers were randomly assigned to a population (see Section 2 for details).

\subsection{Stomach content analysis}

Out of the 2,121 individuals examined in the final dataset, 992 individuals had identifiable prey items in their stomachs (46.8\%). Four fish species, sand eel Ammodytes spp., capelin M. villosus, herring C. harengus and haddock M. aeglefinus, comprised the bulk of the diet content, representing $42.2 \mathrm{~kg}$ of the $44.2 \mathrm{~kg}$ quantified diet content (95.5\%). In total, there were 2,843 identifiable prey items in the datasets, with sand eel being the most abundant and herring being the largest percentage by weight (Figure S2). On average, prey weight significantly differed among species, with haddock being the heaviest, followed by herring, capelin and sand eel (Figure S2).

\subsection{Prey probability and weight in the stomach as a function of sea age, size at age and genetic variation}

The two-component hurdle model revealed a striking negative relationship between the probability of non-empty stomach (e.g. presence of identifiable prey item in the stomach) and prey weight ( $\mathrm{g}$ ) in the stomachs of Atlantic salmon as a function of sea age (Figure 2a,b; Table S2). Young age groups were more likely than older age groups to have prey in their stomach. 1SW individuals were 1.45 (1.02-2.07, $95 \% \mathrm{Cl}, p=0.020)$ and $2.39(1.62-3.51,95 \% \mathrm{Cl}, p<0.001)$ times more likely to have any prey item in their stomachs than $2 \mathrm{SW}$ and 
Non-empty stomach

(a)
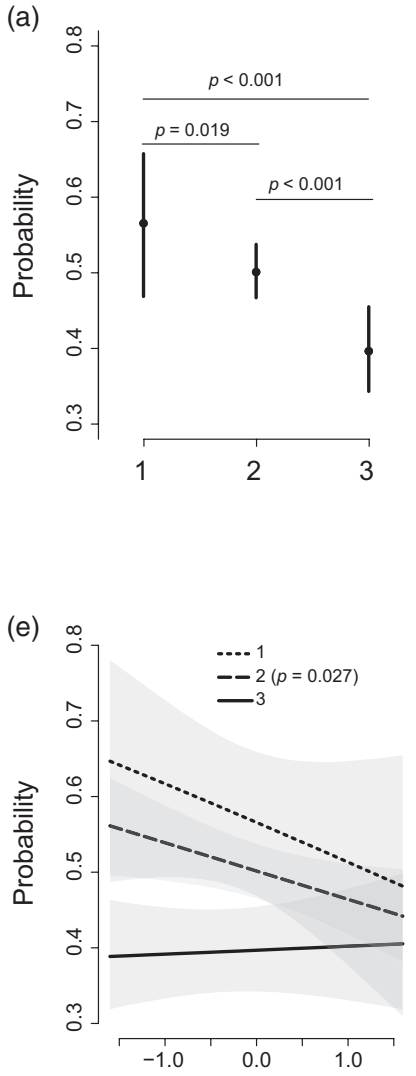

Stomach weight

(b)

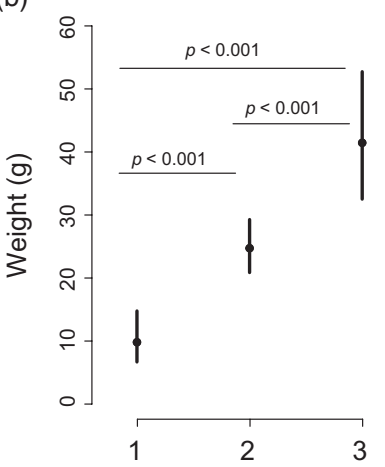

Average prey number (c)

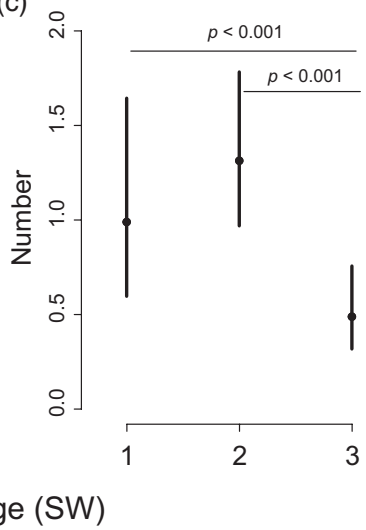

(f)

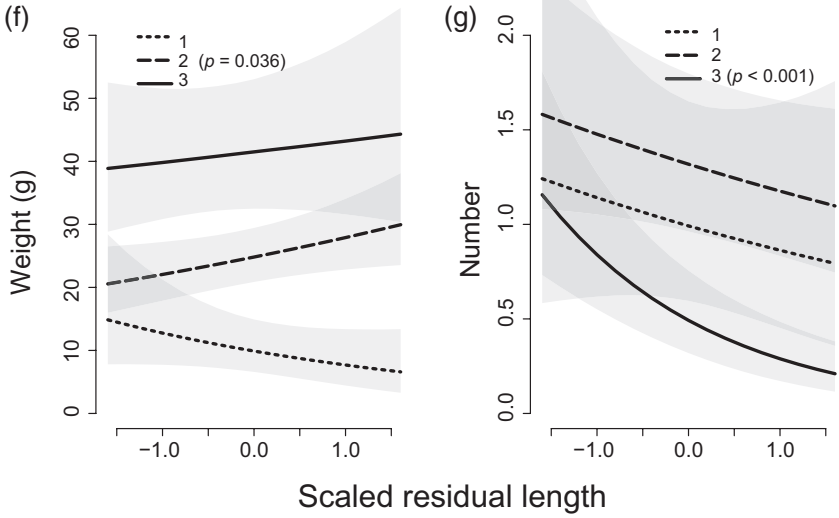

Average prey weight (d)

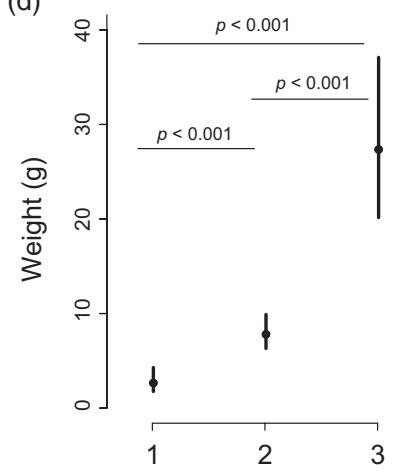

Sea age (SW)

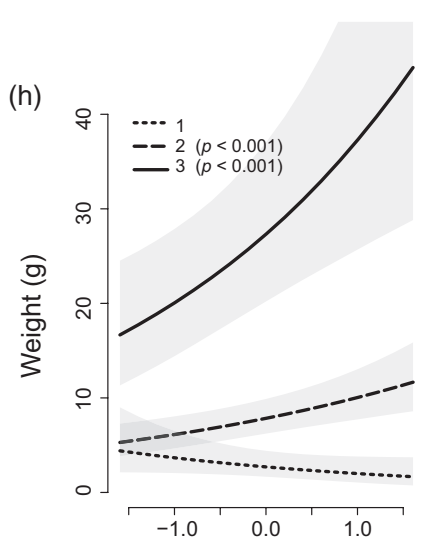

FIGURE 2 Changes in four stomach content variables in relation to sea age (a-d) and size at age (e-h) and, associated 95\% confidence intervals. Only $p<0.1$ are given in the figures. Binned prey weights are given after back transformation to the original scale (i.e., grams). Note that estimates in the last three columns (stomach weight, average prey number and weight) are for non-empty stomachs only

3SW individuals, respectively, and 2SW individuals were 1.65 times more likely to have a prey item in their stomachs than $35 \mathrm{~W}$ fish (1.30-2.08, 95\% Cl, $p<0.001)$. The decrease in non-empty stomach was significantly associated with residual size variation within the 2 SW age group ( $p=0.027$, Figure $2 \mathrm{e}$ ), with larger individuals having empty stomachs more often than the smaller-sized fish in the same age group.

The conditional truncated negative binomial model suggested that young age groups had significantly less prey in their stomachs than older age groups despite a higher likelihood of having non-empty stomachs (Figure $2 \mathrm{~b}$ ). The contrasting results between the zeroinflated and truncated negative binomial components suggested that resource acquisition strategies differed among age groups. The model estimated, on average, $9.9 \mathrm{~g}(6.5-14.9$, 95\% Cl), $24.8 \mathrm{~g}$ (20.8$29.5,95 \% \mathrm{Cl})$, and $41.5 \mathrm{~g}(32.5-53.0,95 \% \mathrm{Cl})$ of prey items in the stomachs of 1SW, 2SW and 3SW fish, respectively, all of which were highly significantly different from one another $(p<0.001)$. Residual length at age also appeared to be a predictor of prey content, but only significantly so in the $2 \mathrm{SW}$ age group ( $p=0.036$, Figure $2 b$ ).

The six $6^{*} L$ allele, which has a higher frequency in populations with an older sea age at maturity (Barson et al., 2015), was associated with an increase in the probability of non-empty stomach in an age-dependent order, with a more pronounced effect in younger age groups (Figure 3a). Allelic substitution from $E$ to $L$ in the six6 genomic region (i.e. change in effect size by changing one allele of the genotype) increased the probability of prey occurring in the stomach by $1.56(0.98-2.48,95 \% \mathrm{Cl}, p=0.057)$ and 1.25 times (1.05-1.49, 95\% $\mathrm{Cl}, p<0.014$ ) in the $1 \mathrm{SW}$ and $2 \mathrm{SW}$ groups, respectively (Figure 3a). Both age groups exhibited significant or suggestive age-dependent genotype effects relative to the $3 \mathrm{SW}$ group ( $p=0.036$ and 0.051 , respectively, Figure 3b). Strikingly, the probability of prey in the stomach in relation to size at age (Figure 2e) was in the opposite direction to the six $6^{*} L$ effect (Figure 3a) despite the two (six6 and size at age) exhibiting a significant positive correlation (Table S3), suggesting the occurrence of complex, contrasting effects of six6 genetic variation across different phenotypic classes.

The conditional model suggested that the $\operatorname{six} 6^{*} L$ allele was also associated with increased total stomach weight in the young age groups (1SW and $2 \mathrm{SW}$ ) but not in the $3 \mathrm{SW}$ group (Figure $3 \mathrm{~b}$ ). The allelic substitution effect from $E$ to $L$ was significant and associated with a 1.87 -fold $(1.20-2.94,95 \% \mathrm{Cl}, p=0.006)$ increase in prey weight in the $1 \mathrm{SW}$ group and was suggestive in the $2 \mathrm{SW}$ group, associated with a $1.14(0.98-1.34,95 \% \mathrm{Cl}, p=0.099)$ increase in prey weight (Figure 3b). 
Non-empty stomach

(a)

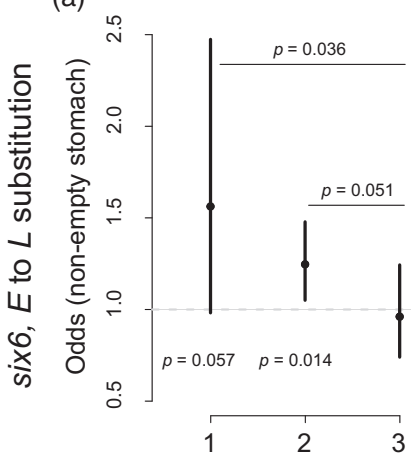

(e)

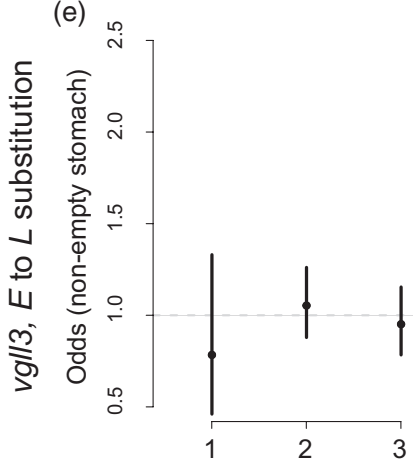

Stomach weight

(b)

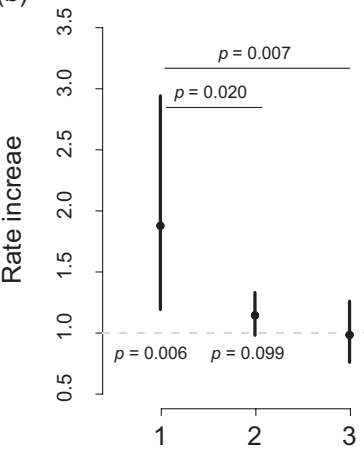

(f)

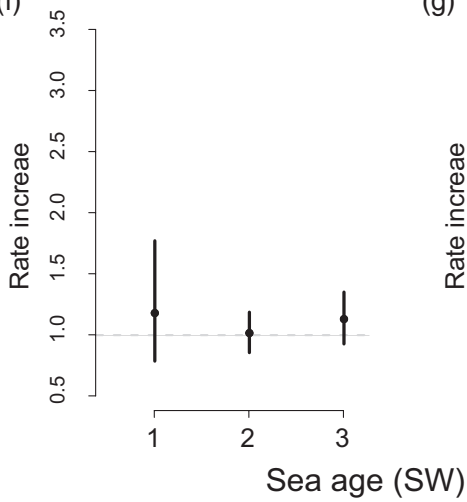

Average prey number

(c)

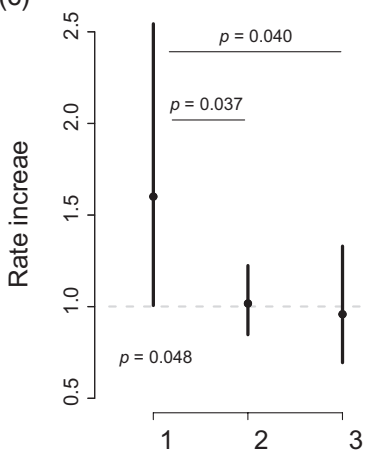

(g)

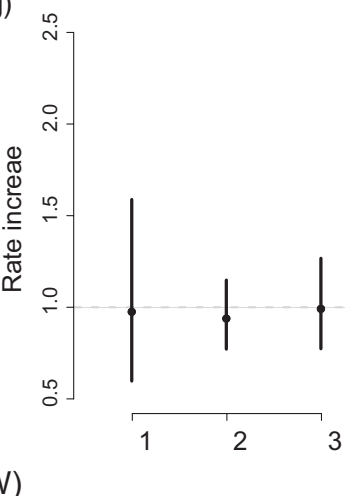

Average prey weight

(d)

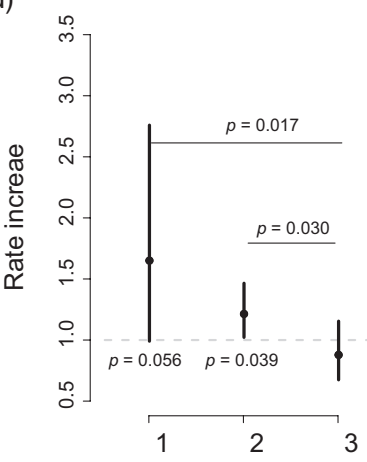

(h)

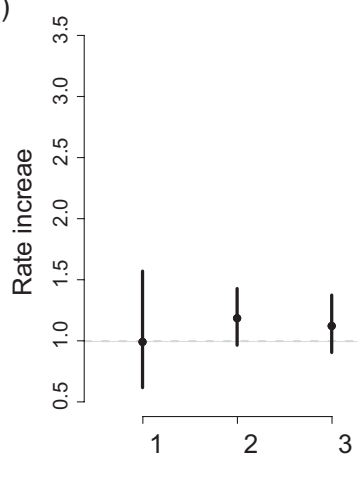

FIGURE 3 Changes in four stomach content variables for differing sea age classes in relation to allelic substitution in six6 (a-d) and vgll3 (e-h) genomic regions and, associated $95 \%$ confidence intervals. Only $p<0.1$ are given in the figures. Note that estimates in the last three columns (stomach weight, average prey number and weight) are for non-empty stomachs only. $p$-values above the plots indicates the signficance of the genetic effects between sea age classes, and below indicates the significance of the genetic effect within age classes. No difference in the response in relation to allelic substitution is indicated by a dashed line

The vgll3 genomic region was not associated with diet content variation, suggesting no causal link between the two (Figure $3 e-h$ ). However, selection on diet may still exert evolutionary change in the vgll3 genomic region, via correlated response to selection (Lande \& Arnold, 1983), as a result of phenotypic covariation between diet and age at maturity and length at age. Accordingly, the effect of vgll3 was significant when these covarying phenotypes were not accounted for in the model (Table S4). Spatio-temporal variance in the dataset was substantial in explaining diet variation in both components of the hurdle model (Table S2, see also Figure S3). In general, diet presence and quantity were the highest at the westerly end of the distribution, with a gradual decrease towards the east. At the temporal scale, sampling days in the middle of the sampling period were associated with a higher presence and quantity of diet in the stomach (Figure S3).

Population of origin was not a significant source of diet variation and explained only a fraction of the total variation in diet content (Table S2, $\Delta$ AIC $=3.91$, LRT $_{2,2057}=0.09, p=0.96$ ). When the analysis was performed with samples assigned to a population of origin with high confidence ( $N=1,372$ ), the variance due to population was similarly small (see Table S5 for total stomach weight as the response variable) and the model was also less parsimonious than a model without the population effect, as assessed by comparing the model fit by difference in their Akaike information criterion and likelihood ratio test $\left(\Delta \mathrm{AIC}=3.42, \mathrm{LRT}_{2,1340}=0.58, p=0.75\right)$. Likewise, the relation between total stomach weight and six6 genetic variation was relatively robust for the full dataset ( $N=2,057$, Table S2) and dataset only including individuals with high population assignment confidence ( $N=1,372$, Table S5).

In our framework, digested, unidentified material in the stomach was not included in the analysis (e.g. Jacobsen \& Hansen, 2001). However, the results were qualitatively similar when digested material was included in the analysis (Table S6). A model including sex was less parsimonious and the term was not included as a parameter in the model ( $\triangle A I C=0.75)$. Finally, when the fit of the genetic models (six6 and vgll3) was compared to the putatively neutral SNPs in the panel, six6 ranked first out 167 , confirming its significance, while vgll3 was only ranked 123rd (Figure S4).

In general, both the number of prey items and the increase in the individual prey weight contributed to the variation in the total stomach weight (Figures 2c,d and 3c,d; Tables S7 and S8). The 3SW age group was associated with significantly fewer prey items $(0.49$ prey items, $0.32-0.76,95 \% \mathrm{Cl}$ ) than the $1 \mathrm{SW}(0.99$ prey items, $0.60-1.65,95 \% \mathrm{Cl}, p=0.004)$ and $2 \mathrm{SW}$ age groups (1.32 prey items, 
$0.96-1.80,95 \% \mathrm{Cl}, p<0.001)$, but the average prey weight was significantly heavier $(27.40 \mathrm{~g}, 21.19-37.20,95 \% \mathrm{Cl})$ than that in the 1SW (2.68 g, 1.65-4.37, 95\% Cl, p<0.001) and 2SW (7.83 g, 6.20$9.88,95 \% \mathrm{Cl}, p<0.001)$ salmon. The average prey weight, but not the prey number, was also significantly different between the $2 \mathrm{SW}$ and 1 SW age groups ( $p<0.001$, Figure $2 c, d)$. Size within age group also significantly influenced the number and size of prey. Larger fish within the 3SW age group had fewer $(p<0.001)$ but heavier $(p<0.001)$ prey items in the diet than smaller fish, and larger $2 \mathrm{SW}$ individuals consumed smaller prey items ( $p<0.001$, Figure $2 \mathrm{~g}$,h; Tables S7 and S8).

The number and size of prey items was also explained by the six 6 genotype in an age-dependent manner, with a more pronounced effect in the relatively young age groups. The $E$ to $L$ substitution in six6 was associated with a 1.60-fold $(1.01-2.56,95 \% \mathrm{Cl}, p=0.048)$ increase in prey number in the $1 \mathrm{SW}$ age group (Figure $3 \mathrm{c}$ ). The allelic substitution was also associated with 1.65 -fold $(0.99-2.77,95 \% \mathrm{Cl}$, $p=0.056)$ and 1.22-fold (1.01-1.47, 95\% Cl, $p=0.040)$ increases in average prey weight in the $1 \mathrm{SW}$ and $2 \mathrm{SW}$ age groups, respectively, which was significant compared to that observed in the $3 \mathrm{SW}$ age group ( $p=0.018$ and 0.030 , respectively, Figure $3 d$ ). Genetic variation in vgll3 was not significantly associated with average individual prey weight or prey number after controlling for age at maturity (Figure 3e-h).

\section{3 | Relative prey composition as a function of sea age, size and genetic variation}

Prey composition varied substantially across different age groups, suggesting a change in prey composition as the fish grow older (Figure 4). In general, older age groups were more likely to prey on herring and haddock (Figure 4a,b), while younger age groups preyed on capelin and sand eel (Figure 4c,d). The same pattern was observed within age groups, (e.g. larger fish within an age group had proportionally more herring and haddock than smaller fish in the same age group) albeit generally not significantly (Figure S5), suggesting that size may be a contributing factor explaining prey composition. In all analyses, spatio-temporal variation was a significant component explaining the prey composition (Table S9).

FIGURE 4 Relative prey composition for the four key prey species, measured as the proportion of each prey species contributing to the stomach content weight, in relation to age at maturity. Note that estimates include only nonempty stomachs. Error bars indicate $95 \%$ confidence intervals
Genetic variation in six6 and vgll3 did not appear to be a strong predictor of prey composition, but some notable associational trends existed for the two genomic regions (Figure S6; Table S9). Particularly, $E$ to $L$ substitution in vgll3 is associated with 1.31 times (0.96-1.79, 95\% Cl, $p=0.089)$ and 1.49 times $(0.96-2.33,95 \%$ $\mathrm{Cl}, p=0.076)$ fewer capelin in the stomach relative to other prey species in the 2SW and 3SW age groups, respectively (Figure S6). Additionally, there was a significant age-dependent preference for capelin over herring associated with the $E$ to $L$ substitution in the six 6 genomic region (Figure S6). When compared to putatively neutral SNPs in the genotyping panel, capelin composition modelled with vgll3 ranked 12th out of 164 SNPs (0.073, Figure S7), a value that is consistent with the analytically inferred $p$-value. Finally, when sea age and size at age were not controlled for, as expected, genetic variation in both the vgll3 and six6 genomic regions explained a substantial portion of the variation also in the relative prey composition (Table S10). This suggests the phenotypic covariance between diet composition and age at maturity may exert a correlated response to selection at the life-history genomic region (i.e. vgll3), despite not being causally linked to diet (i.e. Lande \& Arnold, 1983).

\section{4 | DISCUSSION}

Quantifying resource acquisition via stomach content analysis has been an integral component of ecology and evolution as early as 1900s that is, using Galápagos finches as a model species (Snodgrass, 1902). In this study, we used stomach content from a single time point as a proxy for diet in Atlantic salmon. Diet analysis may be difficult for a number of reasons, such as the challenges in accounting for the diverse nature of diet content data, high percentage of digested food items, difficulty of knowing what is accessible and the diversity of metrics for statistical analysis (e.g. Amundsen \& Sanchez-Hernandez, 2019; Baker, Buckland, \& Sheaves, 2014; Cortés, 1997; de Crespin de Billy, 2000; Rice, 1988). Recently, dietary studies have received renewed interest with methodological development in trophic ecology using stable isotopes (Kawakami, Saito, Nishida, Yamakawa, \& Otake, 2019; MacKenzie et al., 2012), environmental DNA (Taberlet, Bonin, Zinger, $\&$ Coissac, 2018), and in the quantitative analyses of stomach contents (Amundsen \& Sanchez-Hernandez, 2019). In our study, the focus was (a)

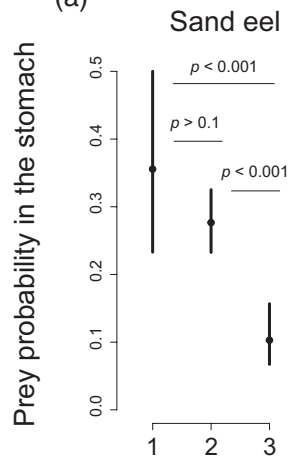

(b)

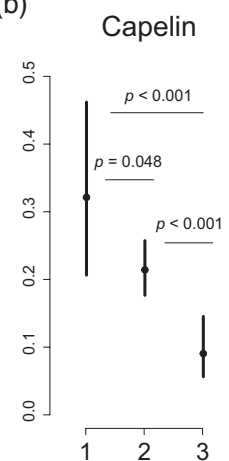

(c)

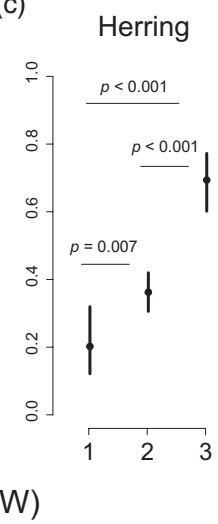

(d)

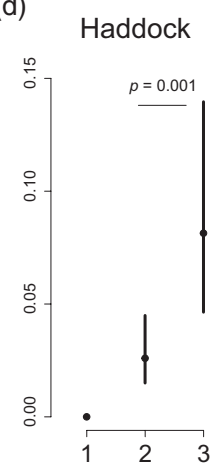


on diet specialization and evolution, where we tested if ontogenetic variation in feeding strategies could be associated with variation in major life-history genes. The relatively small number of prey species in our dataset, all fishes and the small proportion of undigested material provided us with a robust quantification of the diet and a powerful statistical framework with ecologically relevant response variables. The fact that three most common prey species in our dataset (e.g. herring, capelin and sand eel) are from similar trophic levels (independent of size or ontogeny, Bentley et al., 2017; Dommasnes et al., 2001) makes stomach content anlaysis a more suitable alternative for diet assessment, as opposed to, for example, stable isotopes analysis that is useful for detecting long-term trophic variation but insensitive to discern prey species from same trophic levels, nor to assess diet quantity.

Our analyses indicate that diet acquisition strategies in the sea vary with sea age in Atlantic salmon and that this variation is associated with genetic variation in key life-history genomic regions, particularly in the six6 genomic region. The variation in diet explained by sea age and size at age was mostly concordant, suggesting that size is the major driver of diet variation, influencing both the quantity and species composition of prey (Figures 2 and 4). Atlantic salmon prey on heavier but fewer prey as they grow older and larger, which seems to be a strategy that comes at the expense of a reduced prey acquisition probability (Figure 2a,d; Arrington et al., 2002; Huey, Pianka, \& Vitt, 2001). This pattern is consistent with the so-called 'feast and famine' strategy observed among large piscivorous fish species (Arrington et al., 2002). The feast and famine feeding strategy is suggested to be an adaptation to maintain a positive energy balance at a large body size, especially when the acquisition of energyrich food sources is unpredictable (Armstrong \& Schindler, 2011). Large Atlantic salmon appear to adopt this strategy, which is likely beneficial in terms of balancing the increase in energy costs associated with a large body size. A suite of physiological adaptations and metabolic adjustments, such as increased digestion capacity (Armstrong \& Schindler, 2011) and fat storage (Bustard, 1967), may be associated with this strategy (Wang, Hung, \& Randall, 2006). For example, it has been shown that piscivorous species that adopt a feast and famine strategy maintain a large digestive tract, which allows rapid food utilization when abundant prey are encountered (Armstrong \& Schindler, 2011). This physiological trade-off seems to be evolutionarily favourable for large fish when the prey distribution is stochastic despite the energetic costs of sustaining excess and energetically expensive digestive tissue (Armstrong \& Schindler, 2011). The feast and famine strategy in large Atlantic salmon may also be facilitated by other mechanistic processes, such as the trade-off of a lower success rate linked to larger prey or a lower attack rate associated with increasing size. Nonetheless, variation in foraging strategies among different age groups results in a large diet breadth, efficient resource partitioning and reduced intraspecific competition among age groups, which subsequently promotes their coexistence (e.g. Polis, 1984; Smith \& Skulason, 1996; Svanback \& Bolnick, 2007). It is unclear what physiological or behavioural modifications are associated with the differential feeding strategies among the various age groups in Atlantic salmon. Nonetheless, changes in marine food webs may alter the density and composition of prey available to different age groups and hence alter the age-dependent selection landscape, potentially leading to adaptive changes in age structure. Our results confirm the value of Atlantic salmon as a model species to study the evolutionary physiology of starvation and feeding in response to environmental changes in the wild.

Salmon are generally considered to be diet generalists. However, the association between the life-history genomic region six6 and diet acquisition (as well as the non-significant but suggestive acquisition with capelin prey preference and vgll3, see Table S6) indicates that genetically controlled intraspecific diet specialization occurs in Atlantic salmon. This genetic variation may be linked to specialized dietary adaptations (e.g. physiological, morphological or behavioural) allowing the efficient utilization of diverse diet sources, resulting in increased niche breadth and reduced intraspecific competition (Bolnick \& Fitzpatrick, 2007; Bolnick et al., 2003; Dalmo, Ingebrigtsen, \& Bogwald, 1997; Svanback \& Bolnick, 2007). In particular, the six $6^{*} L$ allele was associated with increased content in the stomach, especially in young age groups, which was explained by both an increase in the number of prey items and an increase in the average prey weight in the stomach. Intriguingly, however, the six $6^{*} L$ allele was associated with a larger fish size within all sea ages (Table S3, see also, Barson et al., 2015). Given that larger size at a given sea age is indicative of higher performance and fitness in adult salmon (e.g. Fleming, 1996; Mobley et al., 2020), the six6* $L$ allele (being linked to larger size) may be expected to have a selective advantage over the $E$ allele and is hence predicted to prevail within and among populations as a result of directional selection. However, the six6 genomic region is highly variable within and among populations (Barson et al., 2015; Pritchard et al., 2018), and balancing selection appears to be the pervasive mode of evolution, with both alleles exerting fitness advantage with different life-history strategies (Barson et al., 2015). The results of this study suggest that the genetic variation in six6 locus could be explained by antagonistic pleiotropy along the life cycle of an individual (i.e. fitness trade-offs within the lifetime of an individual associated with the six6 region) or fluctuating selection across generations. For example, genetic variation in six6 may be under balancing selection via antagonistic genetic correlations in diet acquisition over the life cycle. Indeed, some results indicate that individuals having high freshwater growth may show poor seawater growth (Einum, Thorstad, \& Naesje, 2002), prescribing further hypothesis linking it to genetic variation in six6 genomic region.

Although our results suggest superior performance of the six6* $L$ allele at the adult stage, the opposite may be true at earlier life stages, when the prey species composition is substantially different, with significantly more invertebrates in the diet (Haugland et al., 2006; Jacobsen \& Hansen, 2001; Rikardsen et al., 2004), and different ecological drivers affecting performance (Mittelbach, Ballew, Kjelvik, \& Fraser, 2014; Sanchez-Hernandez et al., 2019). For example, if increased metabolic costs are linked with increased prey content in the stomach-a trait associated with six $6^{*} L-$ this may not be an optimal acquisition strategy in younger years (i.e. juveniles prior to, or 
in the early phases of marine migration) when the energy density of available prey cannot compensate for the greater effort (Enberg et al., 2012; McNamara \& Houston, 1996). Such antagonistic genetic correlations between early and late life histories (i.e. genotypeenvironment interactions) in diet acquisition may maintain polymorphism in the region. Alternatively, year-to-year variation in populationspecific (e.g. density dependent) or ecosystem-level processes (i.e. prey composition, food web dynamics) may alter the adaptive landscape of diet acquisition (Smith \& Skulason, 1996), resulting in fluctuating selection and a change in the direction of selection among alleles, which would maintain the genetic variation in the region. Indeed, in the year 2008, returning salmon had a notably older sea age at maturity in northern Norway than that observed in more recent years (i.e. the oldest in the last 20 years, see Anon, 2016). This is consistent with observed patterns that six $6^{*} L$ is linked with larger size, perhaps as a result of providing a selective advantage for that particular year class. However, more research is required to explicitly test this possibility. The six6 genomic region is highly spatially differentiated among populations (Barson et al., 2015; Pritchard et al., 2018). This suggests that any selection acting on six6 as a result of selection on diet acquisition would influence the fitness of populations differentially, correlated with their average allele frequency. Hence, genetic variation in six6 may be linked to the differential survival of populations at sea and should be closely monitored in population management.

The genetic variation in the vgll3 genomic region had no clear effect on diet quantity overall, but there was a marginal ( $p=0.073$, albeit consistent, association with higher capelin content in the stomach (Figures S6 and S7). Capelin is a key component in the Barents Sea ecosystem with critical bottom-up effect (Gjøsæter, Hallfredsson, Mikkelsen, Bogstad, \& Pedersen, 2016), and both salmon post-smolts and returning adults utilize them as a food resource (Rikardsen \& Dempson, 2010, this study) when they migrate through the coastal regions (Gjøsæter et al., 2016). Individuals with the vgll $3^{*} \mathrm{~L}$ allele, which is associated with a later sea age at maturity (Barson et al., 2015), were marginally less likely to feed on capelin, particularly in older age groups (2SW and 3SW). In addition, in contrast to herring, which was the most common prey item in the stomachs of the individuals in the $2 \mathrm{SW}$ and $3 \mathrm{SW}$ age groups (Figure $4 \mathrm{c}$ ), capelin is likely a lower-energy prey item for Atlantic salmon (Elliott \& Gaston, 2008; Hedeholm, Grønkjær, \& Rysgaard, 2011; Renkawitz, Sheehan, Dixon, \& Nygaard, 2015). This supports the notion that vgll ${ }^{*} L$ may contribute to foraging adaptations to support the high-energy demands associated with the larger body size of late maturing fish. However, further research is needed to substantiate this suggestive link and to identify mechanisms driving such a compositional difference.

Overall, genetic variation in both life-history genomic regions appears to have a role in intraspecific diet specialization, but the mechanisms remain to be clarified. Although the underlying mechanism of diet specialization is complex (e.g. Mittelbach et al., 2014) and challenging to disentangle, performance trade-offs across different ecological settings and the life cycle are likely driving the life-history variation associated with these genomic regions. Analyses of datasets collected in the wild may suffer from confounding effects that covary with both the response variable and parameters of interest and generate spurious associations if they are not accounted for. In this study, a highly controlled linear model was employed to account for environmental and intrinsic parameters with potential confounding effects. First, resource availability at sea, for example, the prey species density and distribution, is highly variable across time and space, even at small scales. Likewise, during their return migration, Atlantic salmon may be non-randomly distributed in relation to their life history, genotype and population of origin (Svenning et al., 2019). For example, relatively early run timing is linked to both later maturation (Jonsson \& Jonsson, 2011) and six $6^{*}$ L (Cauwelier, Gilbey, Sampayo, Stradmeyer, \& Middlemas, 2018; Pritchard et al., 2018), a pattern that concordantly holds in our dataset (Table S11). Hence, the analytical framework controlled for spatio-temporal variation and also accounted for nonlinear changes through space and time (Figure S3). Similarly, sea age at maturity and size within an age group exhibited strong links with both diet and genetic variation in the life-history genomic regions. By accounting for these phenotypes in the model, we were able to exclude the possibility of modelling the genetic variation via the effects of these intermediate phenotypes. Therefore, our framework was rather robust to drawbacks related to confounding factors observed in wild settings. Finally, variation in diet due to the population of origin was also accounted for in the model as a random intercept but did not explain significant diet variation at sea (Tables S2 and S5).

On the other hand, evidence for association between diet variation and life-history genomic regions had relatively low statistical support. Therefore, further research is warranted to validate these results. Furthermore, genetic variation outside these two major maturation-timing loci and potential pleiotropic effects remains unexplained, which could be explored with a genome wide approach in future studies. Likewise, similar set-ups at different life-history stages, under different feeding regimes, or in common garden conditions, would help to elucidate the effect of genotypeenvironment interactions that may have been overlooked in this dataset.

Marine ecosystems, which are composed of mostly poikilothermic species, are sensitive and highly responsive to temperaturedriven changes (e.g. Clarke, 2003; Sydeman et al., 2015). The Arctic region is particularly sensitive to global climate change (Polyakov et al., 2010), with significant anthropogenic effects further shaping the marine food webs in the region. Over the last 40 years, the abundance of Atlantic salmon has been declining, and the age structure has been shifting towards a younger age at maturity (Chaput, 2012; Czorlich et al., 2018; Erkinaro et al., 2018). Such changes in demography are likely the result of bottom-up changes in prey community structure, likely fuelled by climateinduced changes to the ecosystem (Frederiksen, Edwards, Richardson, Halliday, \& Wanless, 2006; Todd et al., 2008). In this study, we demonstrated that the inter-individual variation in diet specialization is linked with age structure as well as the genetic variation 
in six6 and vgll3, two genomic regions with substantial influence on life-history variation and population divergence. This heritable intraspecific variation in diet specialization likely plays an important role in salmon life history by both promoting the niche breadth of species and enabling evolutionary responses in populations to changes in food composition. Given that both genomic regions are highly differentiated among populations, evolutionary response and the resulting demographic trajectories likely differ among populations, concordantly. Future work should focus on characterizing the underlying physiological and/or behavioural mechanisms linking genetic variation with salmon diet acquisition to better predict the evolutionary response of populations to changing environments.

\section{ACKNOWLEDGEMENTS}

We acknowledge the Atlantic Sea salmon fishing organizations in Finnmark county, and especially fishers who collected more than 2000 stomachs from wild Atlantic salmon used in this study. We thank Ursula Lönnqvist for laboratory assistance. This project received funding from the Academy of Finland (project numbers 318939, 325964 to T.A., 314254, 314255 to C.R.P.), from the European Union, Kolarctic ENPI CBC project 'Trilateral cooperation on our common resource; the Atlantic salmon in the Barents Region (KO197)' (https://prosjekt.fylkesmannen.no/Kolarcticsalmon), and the Research Council of Norway (project numbers 244086 and 280308). The funders had no role in study design, data collection and analysis, decision to publish or preparation of the manuscript.

\section{AUTHORS' CONTRIBUTIONS}

T.A. conceived the study; M.R., M.-A.S. and T.P. collected the stomach content data and performed the diet analysis; T.A. and M.O. analysed the data; E.N., M.-A.S., V.W., M.O., J.-P.V. took part in Kolarctic ENPI CBC project (KO197) sample collection and microsatellite genetic analysis; L.P., T.A. and C.R.P. optimized and coordinated the targeted SNP genotyping assays; K.H. initiated the collaboration and co-ordinated sample transfer; T.A., C.R.P. and M.-A.S. led the writing of the manuscript. All authors contributed critically to the drafts and gave final approval for publication.

\section{DATA AVAILABILITY STATEMENT}

Data are available from the Dryad Digital Repository https://doi.org/ 10.5061/dryad.cz8w9gj1m (Aykanat et al., 2020).

\section{ORCID}

Tutku Aykanat (iD https://orcid.org/0000-0002-4825-0231

Mikhail Ozerov (iD https://orcid.org/0000-0002-1817-7707

Craig R. Primmer (iD https://orcid.org/0000-0002-3687-8435

\section{REFERENCES}

Amundsen, P. A., \& Sanchez-Hernandez, J. (2019). Feeding studies take guts - Critical review and recommendations of methods for stomach contents analysis in fish. Journal of Fish Biology, 95, 1364-1373. https://doi.org/10.1111/jfb.14151
Anon. (2016). Status of the River Tana salmon populations. Report of the working group on salmon monitoring and research in the Tana River system. Finland: Luke. Retrieved from https://www.luke.fi/wp content/ uploads/2017/05/2016_Tana_status_report_final.pdf

Armstrong, J. B., \& Schindler, D. E. (2011). Excess digestive capacity in predators reflects a life of feast and famine. Nature, 476, 84-87. https://doi.org/10.1038/nature10240

Arrington, D. A., Winemiller, K. O., Loftus, W. F., \& Akin, S. (2002). How often do fishes 'run on empty'? Ecology, 83, 2145-2151. https://doi. org/10.2307/3072046

Aykanat, T., Lindqvist, M., Pritchard, V. L., \& Primmer, C. R. (2016). From population genomics to conservation and management: A workflow for targeted analysis of markers identified using genome-wide approaches in Atlantic salmon Salmo salar. Journal of Fish Biology, 89, 2658-2679. https://doi.org/10.1111/jfb.13149

Aykanat, T., Ozerov, M., Vaha, J. P., Orell, P., Niemela, E., Erkinaro, J., \& Primmer, C. R. (2019). Co-inheritance of sea age at maturity and iteroparity in the Atlantic salmon vgll3 genomic region. Journal of Evolutionary Biology. https://doi.org/10.1111/jeb.13418

Aykanat, T., Rasmussen, M., Ozerov, M., Niemelä, E., Paulin, L., Vähä, J.P., ... Primmer, C. R. (2020). Data from: Life history genomic regions explain differences in Atlantic salmon marine diet specialization. Dryad Digital Repository, https://doi.org/10.5061/dryad.cz8w9gj1m

Ayllon, F., Kjaerner-Semb, E., Furmanek, T., Wennevik, V., Solberg, M. F., Dahle, G., ... Wargelius, A. (2015). The vgll3 locus controls age at maturity in wild and domesticated Atlantic salmon (Salmo salar L.) Males. PLoS Genetics, 11, e1005628. https://doi.org/10.1371/journal. pgen.1005628

Baker, R., Buckland, A., \& Sheaves, M. (2014). Fish gut content analysis: Robust measures of diet composition. Fish and Fisheries, 15, 170-177. https://doi.org/10.1111/faf.12026

Barson, N. J., Aykanat, T., Hindar, K., Baranski, M., Bolstad, G. H., Fiske, P., ... Primmer, C. R. (2015). Sex-dependent dominance at a single locus maintains variation in age at maturity in salmon. Nature, 528, 405-408. https://doi.org/10.1038/nature16062

Bentley, J. W., Serpetti, N., \& Heymans, J. J. (2017). Investigating the potential impacts of ocean warming on the Norwegian and Barents Seas ecosystem using a time-dynamic food-web model. Ecological Modelling, 360, 94-107. https://doi.org/10.1016/j.ecolmodel.2017. 07.002

Bessarab, D. A., Chong, S. W., \& Korzh, V. (2004). Expression of zebrafish six1 during sensory organ development and myogenesis. Developmental Dynamics, 230, 781-786. https://doi.org/10.1002/ dvdy.20093

Bolnick, D. I., Amarasekare, P., Araujo, M. S., Burger, R., Levine, J. M., Novak, M., ... Vasseur, D. A. (2011). Why intraspecific trait variation matters in community ecology. Trends in Ecology \& Evolution, 26, 183192. https://doi.org/10.1016/j.tree.2011.01.009

Bolnick, D. I., \& Araujo, M. S. (2011). Partitioning the relative fitness effects of diet and trophic morphology in the threespine stickleback. Evolutionary Ecology Research, 13, 439-459.

Bolnick, D. I., \& Fitzpatrick, B. M. (2007). Sympatric speciation: Models and empirical evidence. Annual Review of Ecology, Evolution, and Systematics, 38, 459-487. https://doi.org/10.1146/annurev.ecolsys. 38.091206.095804

Bolnick, D. I., Svanback, R., Fordyce, J. A., Yang, L. H., Davis, J. M., Hulsey, C. D., \& Forister, M. L. (2003). The ecology of individuals: Incidence and implications of individual specialization. The American Naturalist, 161, 1-28. https://doi.org/10.1086/343878

Bradbury, I. R., Hamilton, L. C., Rafferty, S., Meerburg, D., Poole, R., Dempson, J. B., ... Bernatchez, L. (2015). Genetic evidence of local exploitation of Atlantic salmon in a coastal subsistence fishery in the Northwest Atlantic. Canadian Journal of Fisheries and Aquatic Sciences, 72, 83-95. https://doi.org/10.1139/cjfas-20140058 
Brooks, M. E., Kristensen, K., van Benthem, K. J., Magnusson, A., Berg, C. W., Nielsen, A., ... Bolker, B. M. (2017). glmmTMB balances speed and flexibility among packages for zero-inflated generalized linear mixed modeling. The R Journal, 9, 378-400. https://doi.org/10.32614/Rj2017-066

Bustard, H. R. (1967). Gekkonid lizards adapt fat storage to desert environments. Science, 158, 1197-1198. https://doi.org/10.1126/science. 158.3805.1197

Campbell, N. R., Harmon, S. A., \& Narum, S. R. (2015). Genotyping-inThousands by sequencing (GT-seq): A cost effective SNP genotyping method based on custom amplicon sequencing. Molecular Ecology Resources, 15, 855-867. https://doi.org/10.1111/1755-0998.12357

Carter, A. J., Goldizen, A. W., \& Tromp, S. A. (2010). Agamas exhibit behavioral syndromes: Bolder males bask and feed more but may suffer higher predation. Behavioral Ecology, 21, 655-661. https://doi. org/10.1093/beheco/arq036

Cauwelier, E., Gilbey, J., Sampayo, J., Stradmeyer, L., \& Middlemas, S. J. (2018). Identification of a single genomic region associated with seasonal river return timing in adult Scottish Atlantic salmon (Salmo salar), using a genome-wide association study. Canadian Journal of Fisheries and Aquatic Sciences, 75, 1427-1435. https://doi. org/10.1139/cjfas-2017-0293

Chaput, G. (2012). Overview of the status of Atlantic salmon (Salmo salar) in the North Atlantic and trends in marine mortality. ICES Journal of Marine Science, 69, 1538-1548. https://doi.org/10.1093/icesjms/ fss013

Claessen, D., \& Dieckmann, U. (2002). Ontogenetic niche shifts and evolutionary branching in size-structured populations. Evolutionary Ecology Research, 4, 189-217.

Clarke, A. (2003). Costs and consequences of evolutionary temperature adaptation. Trends in Ecology \& Evolution, 18, 573-581. https://doi. org/10.1016/j.tree.2003.08.007

Cortés, E. (1997). A critical review of methods of studying fish feeding based on analysis of stomach contents: Application to elasmobranch fishes. Canadian Journal of Fisheries and Aquatic Sciences, 54, 726738. https://doi.org/10.1139/f96-316

Czorlich, Y., Aykanat, T., Erkinaro, J., Orell, P., \& Primmer, C. R. (2018). Rapid sex-specific evolution of age at maturity is shaped by genetic architecture in Atlantic salmon. Nature Ecology \& Evolution, 2, 18001807. https://doi.org/10.1038/s41559-018-0681-5

Dalmo, R. A., Ingebrigtsen, K., \& Bogwald, J. (1997). Non-specific defence mechanisms in fish, with particular reference to the reticuloendothelial system (RES). Journal of Fish Diseases, 20, 241-273. https:// doi.org/10.1046/j.1365-2761.1997.00302.x

Daufresne, M., Lengfellner, K., \& Sommer, U. (2009). Global warming benefits the small in aquatic ecosystems. Proceedings of the National Academy of Sciences of the United States of America, 106, 1278812793. https://doi.org/10.1073/pnas.0902080106

de Crespin de Billy, V. (2000). Biplot presentation of diet composition data: An alternative for fish stomach contents analysis. Journal of Fish Biology, 56, 961-973. https://doi.org/10.1111/j.1095-8649.2000. tb00885.x

Debes, P. V., Piavchenko, N., Ruokolainen, A., Ovaskainen, O., MoustakasVerho, J. E., Parre, N., ... Primmer, C. R. (2019). Large single-locus effects for maturation timing are mediated via condition variation in Atlantic salmon. bioRxiv, 780437. https://doi.org/10.1101/780437

Devictor, V., Clavel, J., Julliard, R., Lavergne, S., Mouillot, D., Thuiller, W., ... Mouquet, N. (2010). Defining and measuring ecological specialization. Journal of Applied Ecology, 47, 15-25. https://doi. org/10.1111/j.1365-2664.2009.01744.x

Dommasnes, A., Christensen, V., Ellertsen, B., Kvamme, C., Melle, W., Nøttestad, L., ... Zeller, D. (2001). An Ecopath model for the Norwegian and Barents Sea. Fisheries impacts on North Atlantic ecosystems: Models and analyses. University of British Columbia Fisheries Center Research Report, 9(4), 213-240.
Einum, S., Thorstad, E. B., \& Naesje, T. F. (2002). Growth rate correlations across life-stages in female Atlantic salmon. Journal of Fish Biology, 60, 780-784. https://doi.org/10.1006/jfbi.2002.1895

Elliott, K. H., \& Gaston, A. J. (2008). Mass-length relationships and energy content of fishes and invertebrates delivered to nestling Thickbilled Murres Uria lomvia in the Canadian Arctic, 1981-2007. Marine Ornithology, 36, 25-34.

Elphinstone, M. S., Hinten, G. N., Anderson, M. J., \& Nock, C. J. (2003). An inexpensive and high-throughput procedure to extract and purify total genomic DNA for population studies. Molecular Ecology Notes, 3, 317-320. https://doi.org/10.1046/j.1471-8286.2003.00397.x

Enberg, K., Jørgensen, C., Dunlop, E. S., Varpe, Ø., Boukal, D. S., Baulier, L., ... Heino, M. (2012). Fishing-induced evolution of growth: Concepts, mechanisms and the empirical evidence. Marine Ecology, 33, 1-25. https://doi.org/10.1111/j.1439-0485.2011.00460.x

Endelman, J. B. (2011). Ridge regression and other kernels for genomic selection with R package rrBLUP. The Plant Genome, 4, 250-255. https://doi.org/10.3835/plantgenome2011.08.0024

Engen, S., \& Stenseth, N. C. (1989). Age-specific optimal diets and optimal foraging tactics: A life-historic approach. Theoretical Population Biology, 36, 281-295. https://doi.org/10.1016/0040-5809(89)90035-X

Erkinaro, J., Czorlich, Y., Orell, P., Kuusela, J., Falkegård, M., Länsman, M., ... Niemelä, E. (2018). Life history variation across four decades in a diverse population complex of Atlantic salmon in a large subarctic river. Canadian Journal of Fisheries and Aquatic Sciences, 76(1), 42-55. https://doi.org/10.1139/cjfas-2017-0343

Erkinaro, J., Dempson, J. B., Julkunen, M., \& Niemelä, E. (1997). Importance of ontogenetic habitat shifts to juvenile output and life history of Atlantic salmon in a large subarctic river: An approach based on analysis of scale characteristics. Journal of Fish Biology, 51, 1174-1185. https://doi.org/10.1111/j.1095-8649.1997.tb01134.x

Fleming, I. A. (1996). Reproductive strategies of Atlantic salmon: Ecology and evolution. Reviews in Fish Biology and Fisheries, 6, 379-416. https://doi.org/10.1007/bf00164323

Fox, L. R., \& Morrow, P. A. (1981). Specialization: Species property or local phenomenon? Science, 211, 887-893. https://doi.org/10.1126/ science.211.4485.887

Frederiksen, M., Edwards, M., Richardson, A. J., Halliday, N. C., \& Wanless, S. (2006). From plankton to top predators: Bottom-up control of a marine food web across four trophic levels. Journal of Animal Ecology, 75, 1259-1268. https://doi.org/10.1111/j.1365-2656.2006. 01148.x

Friedland, K. D., \& Haas, R. E. (1996). Marine post-smolt growth and age at maturity of Atlantic salmon. Journal of Fish Biology, 48, 1-15. https://doi.org/10.1111/j.1095-8649.1996.tb01414.x

Gallardo, M. E., Lopez-Rios, J., Fernaud-Espinosa, I., Granadino, B., Sanz, R., Ramos, C., ... Rodriguez de Cordoba, S. (1999). Genomic cloning and characterization of the human homeobox gene SIX6 reveals a cluster of SIX genes in chromosome 14 and associates SIX6 hemizygosity with bilateral anophthalmia and pituitary anomalies. Genomics, 61, 82-91. https://doi.org/10.1006/geno.1999.5916

Gjøsæter, H., Hallfredsson, E. H., Mikkelsen, N., Bogstad, B., \& Pedersen, T. (2016). Predation on early life stages is decisive for year-class strength in the Barents Sea capelin (Mallotus villosus) stock. ICES Journal of Marine Science: Journal du Conseil, 73, 182-195. https://doi. org/10.1093/icesjms/fsv177

Gotthard, K. (2000). Increased risk of predation as a cost of high growth rate: An experimental test in a butterfly. Journal of Animal Ecology, 69, 896-902. https://doi.org/10.1046/j.1365-2656.2000.00432.x

Hadfield, J. D. (2010). MCMC methods for multi-response generalized linear mixed models: The MCMCgImm R package. Journal of Statistical Software, 33, 1-22.

Halperin, D. S., Pan, C., Lusis, A. J., \& Tontonoz, P. (2013). Vestigial-like 3 is an inhibitor of adipocyte differentiation. Journal of Lipid Research, 54, 473-481. https://doi.org/10.1194/jlr.M032755 
Härkönen, T. (1986). Guide to the otoliths of the bony fishes of the Northeast Atlantic. Hellerup: Danbiu ApS.

Haugland, M., Holst, J., Holm, M., \& Hansen, L. (2006). Feeding of Atlantic salmon (Salmo salar L.) post-smolts in the Northeast Atlantic. ICES Journal of Marine Science, 63, 1488-1500. https://doi.org/10.1016/ j.icesjms.2006.06.004

Hedeholm, R., Grønkjær, P., \& Rysgaard, S. (2011). Energy content and fecundity of capelin (Mallotus villosus) along a 1,500-km latitudinal gradient. Marine Biology, 158, 1319-1330. https://doi.org/10.1007/ s00227-011-1651-5

Heino, M., \& Kaitala, V. (1999). Evolution of resource allocation between growth and reproduction in animals with indeterminate growth. Journal of Evolutionary Biology, 12, 423-429. https://doi. org/10.1046/j.1420-9101.1999.00044.x

Huey, R. B., Pianka, E. R., \& Vitt, L. J. (2001). How often do lizards 'run on empty'? Ecology, 82, 1-7. https://doi.org/10.1890/0012-9658(2001) 082[0001:HODLRO]2.0.CO;2

Hvidsten, N. A., Jensen, A. J., Rikardsen, A. H., Finstad, B., Aure, J., Stefansson, S., ... Johnsen, B. O. (2009). Influence of sea temperature and initial marine feeding on survival of Atlantic salmon Salmo salar postsmolts from the Rivers Orkla and Hals, Norway. Journal of Fish Biology, 74, 1532-1548. https://doi.org/10.1111/j.1095-8649.2009.02219.x

ICES. (2011). Report of the Workshop on Age Determination of Salmon (WKADS). Ireland: Galway.

Jacobsen, J. A., \& Hansen, L. P. (2001). Feeding habits of wild and escaped farmed Atlantic salmon, Salmo salar L., in the Northeast Atlantic. ICES Journal of Marine Science, 58, 916-933. https://doi. org/10.1006/jmsc.2001.1084

Jensen, H., Kiljunen, M., \& Amundsen, P. A. (2012). Dietary ontogeny and niche shift to piscivory in lacustrine brown trout Salmo trutta revealed by stomach content and stable isotope analyses. Journal of Fish Biology, 80, 2448-2462. https://doi.org/10.1111/j.1095-8649.2012.03294.x

Jonsson, B., \& Jonsson, N. (2011). Ecology of Atlantic salmon and brown trout: Habitat as a template for life histories. Dordrecht, The Netherlands: Springer.

Jonsson, N., Jonsson, B., \& Hansen, L. P. (1997). Changes in proximate composition and estimates of energetic costs during upstream migration and spawning in Atlantic salmon Salmo salar. Journal of Animal Ecology, 66, 425-436. https://doi.org/10.2307/5987

Kawakami, T., Saito, T., Nishida, K., Yamakawa, T., \& Otake, T. (2019). Relationships between growth traits and scale stable isotopes $\left(\delta^{13} \mathrm{C}\right.$, $\delta^{15} \mathrm{~N}$ ) of adult chum salmon Oncorhynchus keta in Hokkaido, Japan. Journal of Applied Ichthyology, 35, 570-575.

Lande, R., \& Arnold, S. J. (1983). The measurement of selection on correlated characters. Evolution, 37, 1210-1226. https://doi.org/10.1111/ j.1558-5646.1983.tb00236.x

Lepais, O., Manicki, A., Glise, S., Buoro, M., \& Bardonnet, A. (2017). Genetic architecture of threshold reaction norms for male alternative reproductive tactics in Atlantic salmon (Salmo salar L.). Scientific Reports, 7(1). https://doi.org/10.1038/srep43552

Lin, X., Duan, X., Liang, Y. Y., Su, Y., Wrighton, K. H., Long, J., ... Feng, X. H. (2006). PPM1A functions as a Smad phosphatase to terminate TGFbeta signaling. Cell, 125, 915-928. https://doi.org/10.1016/ j.cell.2006.03.044

MacKenzie, K. M., Trueman, C. N., Palmer, M. R., Moore, A., Ibbotson, A. T., Beaumont, W. R. C., \& Davidson, I. C. (2012). Stable isotopes reveal age-dependent trophic level and spatial segregation during adult marine feeding in populations of salmon. ICES Journal of Marine Science, 69, 1637-1645. https://doi.org/10.1093/icesjms/fss074

McNamara, J. M., \& Houston, A. I. (1996). State-dependent life histories. Nature, 380, 215-221. https://doi.org/10.1038/380215a0

Mittelbach, G. G., Ballew, N. G., Kjelvik, M. K., \& Fraser, D. (2014). Fish behavioral types and their ecological consequences. Canadian Journal of Fisheries and Aquatic Sciences, 71, 927-944. https://doi. org/10.1139/cjfas-2013-0558
Mittelbach, G. G., \& Persson, L. (1998). The ontogeny of piscivory and its ecological consequences. Canadian Journal of Fisheries and Aquatic Sciences, 55, 1454-1465. https://doi.org/10.1139/f98-041

Mobley, K. B., Granroth-Wilding, H., Ellmén, M., Orell, P., Erkinaro, J., \& Primmer, C. R. (2020). Time spent in distinct life history stages has sex-specific effects on reproductive fitness in wild Atlantic salmon. Molecular Ecology, 29(6), 1173-1184. https://doi.org/10.1111/mec. 15390

Mousseau, T. A., Sinervo, B., \& Endler, J. A. (2000). Adaptive genetic variation in the wild. New York, NY: Oxford University Press.

Nakayama, K., Ohashi, J., Watanabe, K., Munkhtulga, L., \& Iwamoto, S. (2017). Evidence for very recent positive selection in mongolians. Molecular Biology and Evolution, 34(8), 1936-1946. https://doi. org $/ 10.1093 / \mathrm{molbev} / \mathrm{msx} 138$

Neaves, P. I., Wallace, C. G., Candy, J. R., \& Beacham, T. D. (2005). CBayes: Computer program for mixed-stock analysis of allelic data. Nanaimo, Canada: Fisheries and Oceans Canada. Retrieved from https://www. pac.dfo-mpo.gc.ca/science/facilities-installations/pbs-sbp/mgl-lgm/ apps/index-eng.html

O'Brien, J. H., Hernandez-Lagunas, L., Artinger, K. B., \& Ford, H. L. (2014). MicroRNA-30a regulates zebrafish myogenesis through targeting the transcription factor Six1. Journal of Cell Science, 127, 2291-2301. https://doi.org/10.1242/jcs.143677

Ozerov, M., Vähä, J.-P., Wennevik, V., Niemelä, E., Svenning, M.-A., Prusov, S., ... Christiansen, B. (2017). Comprehensive microsatellite baseline for genetic stock identification of Atlantic salmon (Salmo salar L.) in northernmost Europe. ICES Journal of Marine Science, 74(8), 2159-2169. https://doi.org/10.1093/icesjms/fsx041

Pella, J., \& Masuda, M. (2001). Bayesian methods for analysis of stock mixtures from genetic characters. Fishery Bulletin, 99, 151-167.

Pershing, A. J., Alexander, M. A., Hernandez, C. M., Kerr, L. A., Le Bris, A., Mills, K. E., ... Thomas, A. C. (2015). Slow adaptation in the face of rapid warming leads to collapse of the Gulf of Maine cod fishery. Science, 350, 809-812. https://doi.org/10.1126/science.aac9819

Pethon, P., \& Nyström, B. O. (2005). Aschehougs store fiskebok: Norges fisker i farger. Oslo: Aschehoug.

Polis, G. A. (1984). Age structure component of niche width and intraspecific resource partitioning - Can age-groups function as ecological species. The American Naturalist, 123, 541-564. https://doi. org $/ 10.1086 / 284221$

Polyakov, I. V., Timokhov, L. A., Alexeev, V. A., Bacon, S., Dmitrenko, I. A., Fortier, L., ... Toole, J. (2010). Arctic ocean warming contributes to reduced polar ice cap. Journal of Physical Oceanography, 40, 2743-2756. https://doi.org/10.1175/2010jpo4339.1

Pritchard, V. L., Makinen, H., Vaha, J. P., Erkinaro, J., Orell, P., \& Primmer, C. R. (2018). Genomic signatures of fine-scale local selection in Atlantic salmon suggest involvement of sexual maturation, energy homeostasis and immune defence-related genes. Molecular Ecology, 27, 2560-2575. https://doi.org/10.1111/mec.14705

R Core Team. (2018). R: A language and environment for statistical computing. Vienna, Austria: R Foundation for Statistical Computing. Retrieved from https://www.R-project.org/

Renkawitz, M. D., Sheehan, T. F., Dixon, H. J., \& Nygaard, R. (2015). Changing trophic structure and energy dynamics in the Northwest Atlantic: Implications for Atlantic salmon feeding at West Greenland. Marine Ecology Progress Series, 538, 197-211. https://doi.org/10.3354/ meps11470

Reznick, D. (2016). Hard and soft selection revisited: How evolution by natural selection works in the real world. Journal of Heredity, 107, 3-14. https://doi.org/10.1093/jhered/esv076

Reznick, D., \& Endler, J. A. (1982). The impact of predation on life history evolution in trinidadian guppies (Poecilia Reticulata). Evolution, 36, 160-177. https://doi.org/10.1111/j.1558-5646.1982.tb05021.x

Reznick, D. N., \& Ghalambor, C. K. (2001). The population ecology of contemporary adaptations: What empirical studies reveal about 
the conditions that promote adaptive evolution. Genetica, 112, 183-198.

Rice, J. C. (1988). Repeated cluster analysis of stomach contents data: Method and application to diet of cod in NAFO division 3L. Environmental Biology of Fishes, 21, 263-277. https://doi.org/10.1007/ bf00000375

Ridgeway, A. G., \& Skerjanc, I. S. (2001). Pax3 is essential for skeletal myogenesis and the expression of Six1 and Eya2. Journal of Biological Chemistry, 276, 19033-19039. https://doi.org/10.1074/jbc.M0114 91200

Rikardsen, A. H., \& Dempson, J. B. (2010). Dietary life-support: The food and feeding of Atlantic salmon at sea. Atlantic Salmon Ecology (pp. 115-143). Chichester, UK: Wiley-Blackwell.

Rikardsen, A. H., Haugland, M., Bjorn, P. A., Finstad, B., Knudsen, R., Dempson, J. B., ... Holm, M. (2004). Geographical differences in marine feeding of Atlantic salmon post-smolts in Norwegian fjords. Journal of Fish Biology, 64, 1655-1679. https://doi.org/10.1111/j.1095-8649. 2004.00425.x

Sanchez-Hernandez, J., Nunn, A. D., Adams, C. E., \& Amundsen, P. A. (2019). Causes and consequences of ontogenetic dietary shifts: A global synthesis using fish models. Biological Reviews of the Cambridge Philosophical Society, 94, 539-554. https://doi.org/10.1111/brv. 12468

Serikaku, M. A., \& Otousa, J. E. (1994). Sine oculis is a homeobox gene required for drosophila visual-system development. Genetics, 138, 1137-1150.

Sexton, J. P., Montiel, J., Shay, J. E., Stephens, M. R., \& Slatyer, R. A. (2017). Evolution of ecological niche breadth. Annual Review of Ecology, Evolution, and Systematics, 48, 183-206. https://doi.org/10.1146/ annurev-ecolsys-110316-023003

Smith, T. B., \& Skulason, S. (1996). Evolutionary significance of resource polymorphisms in fishes, amphibians, and birds. Annual Review of Ecology and Systematics, 27, 111-133. https://doi.org/10.1146/annurev. ecolsys.27.1.111

Snodgrass, R. E. (1902). The relation of the food to the size and shape of the bill in the galapagos genus geospiza. The Auk, 19, 4. https://doi. org $/ 10.2307 / 4069598$

Somervuo, P., Koskinen, P., Mei, P., Holm, L., Auvinen, P., \& Paulin, L. (2018). BARCOSEL: A tool for selecting an optimal barcode set for high-throughput sequencing. BMC Bioinformatics, 19, 257. https:// doi.org/10.1186/s12859-018-2262-7

Svanback, R., \& Bolnick, D. I. (2007). Intraspecific competition drives increased resource use diversity within a natural population. Proceedings of the Royal Society B: Biological Sciences, 274, 839-844. https://doi.org/10.1098/rspb.2006.0198

Svanback, R.,\& Persson, L. (2004). Individualdietspecialization, nichewidth and population dynamics: Implications for trophic polymorphisms. Journal of Animal Ecology, 73, 973-982. https://doi.org/10.1111/ j.0021-8790.2004.00868.x

Svenning, M.-A., Falkegård, M., Niemelä, E., Vähä, J.-P., Wennevik, V., Ozerov, M., ... Gomez-Uchida, D. (2019). Coastal migration patterns of the four largest Barents Sea Atlantic salmon stocks inferred using genetic stock identification methods. ICES Journal of Marine Science, 76(6), 1379-1389. https://doi.org/10.1093/icesjms/ fsz114

Sydeman, W. J., Poloczanska, E., Reed, T. E., \& Thompson, S. A. (2015). Climate change and marine vertebrates. Science, 350, 772-777. https://doi.org/10.1126/science.aac9874
Taberlet, P., Bonin, A., Zinger, L., \& Coissac, E. (2018). Environmental DNA: For biodiversity research and monitoring. Oxford: Oxford University Press.

Taranger, G. L., Carrillo, M., Schulz, R. W., Fontaine, P., Zanuy, S., Felip, A., ... Hansen, T. (2010). Control of puberty in farmed fish. General and Comparative Endocrinology, 165, 483-515. https://doi.org/10.1016/ j.ygcen.2009.05.004

Thorpe, J. E., Mangel, M., Metcalfe, N. B., \& Huntingford, F. A. (1998). Modelling the proximate basis of salmonid life-history variation, with application to Atlantic salmon, Salmo salar L. Evolutionary Ecology, 12, 581-599. https://doi.org/10.1023/A:1022351814644

Todd, C. D., Hughes, S. L., Marshall, C. T., MacLean, J. C., Lonergan, M. E., \& Biuw, E. M. (2008). Detrimental effects of recent ocean surface warming on growth condition of Atlantic salmon. Global Change Biology, 14, 958-970. https://doi.org/10.1111/j.1365-2486.2007.01522.x

Toy, J., Yang, J. M., Leppert, G. S., \& Sundin, O. H. (1998). The Optx2 homeobox gene is expressed in early precursors of the eye and activates retina-specific genes. Proceedings of the National Academy of Sciences of the United States of America, 95, 10643-10648. https:// doi.org/10.1073/pnas.95.18.10643

Vähä, J.-P., Erkinaro, J., Niemelä, E., Primmer, C., Saloniemi, I., Falkegård, M., ... Brørs, S. (2011). Temporally stable population-specific differences in run timing of one-sea-winter Atlantic salmon returning to a large river system: Run timing of Atlantic salmon within a river system. Evolutionary Applications, 4(1), 39-53. https://doi.org/10.1111/j.17524571.2010.00131.x

Vähä, J.-P., Wennevik, V., Ozerov, M., Diaz-Fernandez, R., Unneland, L., Haapanen, K., ... Ustyuzhinsky, G. (2014). Genetic structure of Atlantic salmon in the Barents region and genetic stock identification of coastal fishery catches from Norway and Russia [online]. Kolarctic ENPI CBC Kolarctic salmon project (KO197) report. Retrierved from www.fylke smannen.no/kolarcticsalmon

Wang, T., Hung, C. C., \& Randall, D. J. (2006). The comparative physiology of food deprivation: From feast to famine. Annual Review of Physiology, 68, 223-251. https://doi.org/10.1146/annurev.physiol.68. 040104.105739

Werner, E. E., \& Gilliam, J. F. (1984). The ontogenetic niche and species interactions in size-structured populations. Annual Review of Ecology and Systematics, 15, 393-425. https://doi.org/10.1146/annurev. es.15.110184.002141

Wood, S. N. (2011). Fast stable restricted maximum likelihood and marginal likelihood estimation of semiparametric generalized linear models. Journal of the Royal Statistical Society Series B-Statistical Methodology, 73, 3-36. https://doi.org/10.1111/j.1467-9868.2010.00749.x

\section{SUPPORTING INFORMATION}

Additional supporting information may be found online in the Supporting Information section.

How to cite this article: Aykanat T, Rasmussen M, Ozerov M, et al. Life-history genomic regions explain differences in Atlantic salmon marine diet specialization. J Anim Ecol. 2020;89: 2677-2691. https://doi.org/10.1111/1365-2656.13324 